\title{
IJMOR
}

International Journal of Medical and Clinical Research

ISSN: 0976-5530 \& E-ISSN: 0976-5549, Volume 2, Issue 2, 2011, pp-72-77

Available online at http://www.bioinfo.in/contents.php?id=39

\section{IN VITRO DISSOLUTION AND PILOT PHARMACOKINETIC STUDIES OF ACETYLSALICYLIC ACID FROM AN ORALLY DISINTEGRATING TABLET FORMULATION OF LOW-DOSE ASPIRIN}

\author{
YOUSIF ROJEAB ${ }^{1,{ }^{*},}$, SHANE MARTIN B. ${ }^{2}$, ROBIN WHITE$^{3}$, SUSAN MONTENERY ${ }^{3}$, \\ MARY MCWILLIAMS ${ }^{3}$, MARJORIE WALKER ${ }^{3}$ AND DAVID KISOR ${ }^{1}$ \\ 1Department of Pharmaceutical and Biomedical Sciences, \\ 2Department of Pharmacy Practice, College of Pharmacy, Ohio Northern University, Ada, Ohio, 45810, USA \\ ${ }^{3}$ Department of Nursing, Ohio Northern University, Ada, Ohio, 45810, USA \\ "Corresponding Author: E-mail: y-rojeab@onu.edu, Tel: +1-419-772-3957, Fax: +1-419-772-1917
}

Received: November 21, 2011; Accepted: December 01, 2011

\begin{abstract}
Purpose: Low-dose aspirin (acetylsalicylic acid; ASA) is in routine use today in preventing myocardial infarction and cardiovascular events. Fasprin $囚$ (ASA, $81 \mathrm{mg}$ ) is a new orally disintegrating tablet formulation of low-dose ASA (ODA) that was designed as a fast-acting, quick-dissolving solid dosage form. The purpose of this work was to (1) evaluate, comparatively, the in vitro dissolution, and (2) evaluate the absorption kinetics of ASA in healthy adults following oral administration of the ODA product.

Methods: USP type II dissolution apparatus was implemented in the dissolution studies. For the pharmacokinetic studies, a single ODA dose was administered and blood samples were collected and analyzed for ASA content using a validated HPLC method. Absorption-related pharmacokinetic parameters were estimated using WinNonlin®.

Results: Dissolution rate and extent of ASA from the ODA formulation were either higher than or similar to those from leading aspirin-containing products. Noncompartmental pharmacokinetic analysis of ASA plasma profiles from the ODA product revealed a lag-time of at least three minutes. The maximum concentration $\left(C_{\max }\right)$ of $A S A$ was $0.61 \mu \mathrm{g} / \mathrm{mL}$ and the time of $\mathrm{C}_{\max }\left(\mathrm{t}_{\max }\right)$ ranged from 15 - 75 minutes. The elimination rate constant of ASA was $0.0245 \mathrm{~min}^{-1}$, corresponding to a terminal $t \frac{1}{2}$ of 28.3 minutes.

Conclusion: The ODA product demonstrated favorable dissolution compared to some leading ASA-containing products. It also provided systemic concentration of ASA at a relatively early time. While the overall absorption kinetics of the ODA product was generally comparable to those from other low-dose ASA-containing products, a direct product comparison is warranted.
\end{abstract}

Keywords- low-dose aspirin, Fasprin ${ }^{\circledR}$, ASA, dissolution, pharmacokinetics, absorption

\section{Introduction}

In 1988, the United States Food and Drug Administration moved forward on approving the use of aspirin (acetylsalicylic acid; ASA) for reduction of the risk of a second or subsequent myocardial infarction, and prevention of an initial incidence of myocardial infarction (Bayer HealthCare LLC 2008; Food and Drug Administration 2008). This along with the approval of ASA as an agent to prevent transient ischemic attacks and stroke in men moved aspirin beyond its antiinflammatory indication. Since that time, ASA has been shown time and time again to be effective in preventing myocardial infarction in a number of patient populations. A decade later, the results of studies further supported the effectiveness of ASA, this time in prevention of cardiovascular events in patients at risk [1]. In 2005, the benefits of ASA use in women with respect to lowering the risk of stroke were documented [2]. To this day, ASA is recommended by the American Heart Association and the U.S. Preventive Services Task Force for patients at moderate risk for cardiovascular events (American Heart Association 2008; United States Department of Health and Human Services).

The mechanism of action of ASA involved permanent inhibition of cyclooxygenase1 - dependent platelet aggregation [3]. Specifically, ASA irreversibly acetylates the cyclooxygenase 1 enzyme at a serine side chain [4, 5]. This acetylation of the enzyme inhibits the synthesis of thromboxane $A_{2}$, a key mediator in platelet activation, from arachidonic acid [5]. Owing to its irreversible effect on platelets aggregation, small doses of ASA administered chronically should be as effective as much larger doses [6].

In addition to its protective indications within the cardiovascular system, use of daily ASA for about 5 years has been shown to be effective in primary prevention of colorectal cancer in randomized controlled trials, with a latency of about 10 years [7]. While doses 
required to produce those preventive effects in colorectal cancer were relatively high $(300-500 \mathrm{mg})$, more recent studies on ASA taken at lower doses $(75-300 \mathrm{mg})$ daily for several years has been shown to reduce long-term incidence and mortality due to colorectal cancer. Benefit was greatest for cancers of the proximal colon, which are not otherwise prevented effectively by screening with sigmoidoscopy or colonoscopy [8]. These recent finding could open the door for yet another indication to be added to the indications list for ASA, a molecule which is over a 100 years old.

Fasprin ${ }^{\circledR}$ (ASA, $81 \mathrm{mg}$ ) is a new orally disintegrating tablet formulation of low-dose ASA (ODA) that was introduced to the market in recent years. The purpose of the product was to present a fast-acting, quick-dissolving solid dosage form of ASA that might be especially valuable in situations when a fast onset of action is desirable. Therefore, the purposes of this study were to (1) evaluate the dissolution characteristics, in vitro, of various leading ASA-containing products relative to those from the ODA product, and (2) evaluate the absorption kinetics of ASA in healthy adult subjects following oral administration of Fasprin $®$ (ODA product), with emphasis on determining the time of the earliest systemic exposure of ASA. The plasma-concentration versus time data for ASA were constructed and examined to determine the pharmacokinetic parameter estimates of ASA provided by the ODA product. As of today, this is the first attempt to characterize the dissolution properties or pharmacokinetics of this dosage form.

\section{Methods \\ In Vitro Dissolution Studies}

United States Pharmacopeia (USP) Dissolution apparatus type II was employed in the in vitro dissolution studies. Each dosage form ( $n=5-7)$ of either the ODA product, $81 \mathrm{mg}$; Aspirin, $325 \mathrm{mg}$ (Bayer); chewable Aspirin, $81 \mathrm{mg}$ (Bayer) or enteric-coated Aspirin, $81 \mathrm{mg}$ (Bayer) tablets were placed in $500 \mathrm{ml}$ of $0.1 \mathrm{~N} \mathrm{HCl}$ as the dissolution medium. The temperature was maintained at $37 \pm 1^{\circ} \mathrm{C}$ with a circulating water-bath. The dissolution medium was continuously stirred with paddles at $50 \mathrm{rpm}$. One milliliter sample aliquots were withdrawn at predetermined time points up to $120 \mathrm{~min}$, filtered through 0.45 Im syringe filters, adequately diluted and analyzed by HPLC for ASA concentrations. Each withdrawn sample was replaced by an equal volume of temperature-equilibrated fresh dissolution medium. This procedure was slightly modified for the enteric-coated tablets, as described by Gjellan et al. [9]. Briefly, each tablet was placed in a volume of $375 \mathrm{ml}$ of $0.1 \mathrm{~N} \mathrm{HCl}$ for 2 hours. Then, $125 \mathrm{ml}$ of $0.2 \mathrm{M} \mathrm{Na}_{3} \mathrm{PO}_{4}$ was added. The resulting $\mathrm{pH}$ of $7.1-7.2$ was adjusted with $2 \mathrm{M} \mathrm{HCl}$ to a $\mathrm{pH}$ of 6.8. No ASA was released during the first 2 hours as evidenced by samples collected every 30 min within this period. Data reported for ASA dissolution from this dosage form represent those collected 5 minutes after the medium switch and up to 120 minutes.
The Rate and extent of ASA dissolution from all tablets, upon normalizing by the dose, were calculated and the dissolution profiles were constructed. The label strengths of the products were assumed to be $100 \%$.

The statistical significance of differences in the rate and extent of dissolution from the various dosage forms was evaluated by ANOVA and Tukey's post-hoc test at $P$ value of $<0.05$, using Minitab (v.15, Minitab Inc., State College, Pennsylvania).

\section{Pharmacokinetic Studies}

The pharmacokinetics of ASA from the ODA product was studied in healthy volunteers. The study was approved by the Ohio Northern University Institutional Review Board as a single-center, open-label, single-dose pharmacokinetic study. Thirteen healthy adult subjects were enrolled into the study; however, three subjects did not receive the study drug as venous blood access was not achieved. Of the ten subjects completing the study, three were male subjects and seven were females. The average age of the subjects was $28.2 \pm 11.9$ years (mean \pm standard deviation), ranging from $21-54$ years (Table 1).

Each subject underwent screening and was defined as healthy based on medical/laboratory history and physical examination. Female subjects had a negative pregnancy test on study day. Subjects were not taking any medications and had not received any ASA or ASAcontaining products within 14 days of the study day. All subjects were non-smokers. Five subjects fasted for at least eight hour prior to administration of the ODA product.

On the scheduled study day, each subject reported to the research center. Each subject was placed in the supine position and the upper torso was inclined to 30 to 45 degrees. Venous access was gained through the insertion of an 18- or 20-gauge venous catheter into an antecubital vein.

The ODA product was supplied by Improvita Inc., Cleveland, Ohio, while the other aspirin-containing dosage forms were purchased from a local community Pharmacy. Each subject received a single $81 \mathrm{mg}$ dose of the ODA product. The dose was administered as directed by the product labeling. Specifically, each subject placed a single tablet on the tongue and allowed saliva to dissolve the tablet. Subjects indicated to the investigators the time at which the drug had completely disintegrated (no "grittiness"). Access to food or water was not allowed during the blood collection period of 120 minutes.

\section{Plasma Analysis and HPLC Method}

Four milliliters of blood were collected through the venous catheter prior to the ODA product administration and at $1,3,5,7,10,15,20,25,30,35,40,45,60,75$, 90 , and 120 minutes after administration. Blood was collected in tubes containing sodium heparin. The blood was centrifuged within 15 minutes of collection at 3,500 rpm for ten minutes. Plasma was then transferred to 
storage tubes and stored at $-80^{\circ} \mathrm{C}$ until analysis for ASA was performed (within 21 days of collection).

A high performance liquid chromatography (HPLC) assay for quantification of ASA in human plasma was developed based on the method of Benedek et al. [10], with slight modification. An internal standard of o-anisic acid $(0.25 \mu \mathrm{g} / \mathrm{mL})$ was mixed with samples containing ASA in 1:1 ratio (v:v). Base-line resolution was achieved and peak height ratios were plotted against the corresponding analyte concentrations. The slopes of the curves and the y-intercepts were determined by linear regression. The assay linearity was established over the full concentration range for ASA. Calibration curves of ASA were prepared in human plasma. Briefly, $160 \mu \mathrm{L}$ of blank human plasma, obtained from the healthy volunteers, was mixed with $40 \mu \mathrm{L}$ of ASA $(0.125,0.25$, $0.5,2.5$ and $5 \mu \mathrm{g} / \mathrm{mL}$ ) containing solutions. To that, 400 $\mu \mathrm{L}$ of acetonitrile was added to precipitate the plasma proteins. The mixture was first mixed for 20 seconds then centrifuged at $13,000 \mathrm{rpm}$ for one minute. Three hundred $\mu \mathrm{L}$ of the clear supernatant was withdrawn and evaporated to dryness by blowing nitrogen gas at 50 psi. The residue was reconstituted with $100 \mu \mathrm{L}$ of the mobile phase and mixed with an equal volume of the internal standard and injected into the HPLC. For preparation of drug-containing samples for HPLC analysis, $200 \mu \mathrm{l}$ of plasma was mixed with $400 \mu$ of acetonitrile. The remainder of the procedure was similar to that of preparation of the calibration curve samples described above. The coefficient of variation for the assay was defined within and between days with $1.92 \%$ and $5.18 \%$ intra-day $(\mathrm{n}=3)$ and inter-day $(\mathrm{n}=9)$ variability, respectively. Variability of less than $10 \%$ was generally considered acceptable.

\section{Pharmacokinetic Data Analysis}

Noncompartmental pharmacokinetic analysis of the plasma-concentration versus time data for ASA was performed using WinNonlin ${ }^{\circledR} \quad$ (v.2.1; $\quad$ Pharsight Corporation, Mountain View, California). For pharmacokinetic analysis of individual patient data, the labeled strength of the ODA product was assumed to be $100 \%$. In this analysis, the observed maximum concentration $\left(\mathrm{C}_{\max }\right)$ and the time of the maximum concentration $\left(t_{\max }\right)$ were the observed values from the plasma concentration-time profiles. The elimination rate constant ( $\square \mathrm{z}$ ) was estimated using linear regression of the terminal In (concentration) versus time data (minimum of three data points). The terminal $t \frac{1}{2}$ was calculated as $0.693 /$ zz. The pharmacokinetic analyses for ASA included calculation of the area under the plasmaconcentration versus time curve from time zero until the time of the last measurable plasma concentration ( $\mathrm{C}_{\text {last; }}$; $\mathrm{AUC}_{0 \rightarrow t}$ ) using the linear trapezoidal rule. The area under the plasma-concentration versus time curve from the time of the last measurable ASA concentration to infinite time $\left(A \cup C_{t \rightarrow \infty}\right)$ was calculated as $C_{\text {last }} \| \mathrm{Z}$, and the area under the curve from zero to infinity $\left(\mathrm{AUC}_{0 \rightarrow \infty}\right)$ was calculated as the sum of $\mathrm{AUC}_{0 \rightarrow t}$ and $\mathrm{AUC}_{t \rightarrow \infty}$. The clearance of $\mathrm{ASA}(\mathrm{CL} / \mathrm{F})$ was calculated as the administered dose divided by $\mathrm{AUC}_{0 \rightarrow \infty}$.

As this was a single-drug, non-comparative study, the pharmacokinetic parameter estimates for ASA were summarized using descriptive statistics. The $C_{\max }$ was presented as the mean \pm S.D. (standard deviation), while the $t_{\max }$ was summarized by presenting the median value and the minimum and maximum values (range). The terminal elimination rate constant (पz) was presented as the mean \pm S.D. and the terminal $t_{1} / 2$ was presented as the harmonic mean value. The $\mathrm{AUC}_{0 \rightarrow \infty}$ and $\mathrm{CL} / \mathrm{F}$ were presented as the mean \pm S.D.

\section{Results \\ Dissolution Studies:}

The Rate of ASA dissolution of $3.53 \pm 0.29 \% / \mathrm{min}$ from the ODA formulation was significantly higher than those from Bayer's Chewable Aspirin 81 mg, Bayer's EntericCoated Aspirin $81 \mathrm{mg}$ and Bayer's Aspirin $325 \mathrm{mg}$ of $2.71 \pm 0.42,2.49 \pm 0.46$ and $2.07 \pm 0.25 \% / \mathrm{min}$, respectively (Fig. (1) and Table 2). The extent of ASA dissolution from the ODA formulation was $92.03 \pm 6.05$ $\%$, comparable to that from Bayer's Enteric-Coated tablet, $88.05 \pm 5.68 \%$, but significantly higher than that from Bayer's Aspirin $325 \mathrm{mg}$ and Bayer's Chewable Aspirin $81 \mathrm{mg}$ of $82.24 \pm 3.57$ and $76.08 \pm 10.19 \%$, respectively (Fig. (1) and Table 2). Over the sampling period, the extent of ASA dissolved from all formulations started to reach a plateau after 30 minutes from the beginning of the dissolution process.

\section{Pharmacokinetic Studies:}

Subjects were requested to indicate to the investigators when they perceived that the dose of the ODA product had completely disintegrated on their tongue. The average time for complete disintegration of the ODA product $\left(\right.$ Fasprin $^{\circledR}$ ) was $111.2 \pm 65.2$ seconds. The time of disintegration ranged from 45 to 235 seconds (Table 3). The ODA product began to disintegrate immediately upon administration.

In all subject, there was at least a three-minute lag-time before absorption of ASA was noted. Five of ten subjects had quantifiable ASA concentrations at five minutes, while seven of ten subjects had quantifiable ASA concentrations at seven minutes. By 15 minutes, all subjects had quantifiable ASA concentrations (Fig. (2)). In general, the concentrations of ASA increased with time as expected from extravascular dosing, with a maximum concentration occurring typically between 20 and 40 minutes, followed by concentrations decreasing with time in a monoexponential fashion. Fig. (2) presents the ASA concentration versus time data for all but one subject. Data from this subject was excluded from analysis as an outlier (Dixon's test) due to an abnormal absorption profile (data not shown) [11]. The time of the maximum concentration ( $t_{\max }$ ) of ASA ranged from 25 to 75 minutes, with a corresponding $C_{\max }$ of $0.61 \pm 0.34$ $\mu \mathrm{g} / \mathrm{mL}$ (Table 4). The terminal (elimination) rate constant of ASA was $0.0245 \pm 0.0078 \mathrm{~min}^{-1}$ and the harmonic mean $t_{1} / 2$ of $A S A$ in the subjects averaged 28.3 minutes. 
The clearance of ASA with the bioavailability (F) unknown (CL/F) was $2282.4 \pm 636 \mathrm{~mL} /$ minute (Table 4). The area under the ASA concentration versus time curve from time zero to infinity, $A \cup C_{0 \rightarrow \infty}$, was $37.9 \pm 10.1$ $\mu \mathrm{g} / \mathrm{mL} \times \mathrm{min}$. The measured ASA concentration versus time data covered $86.4 \%$ of the $\mathrm{AUC}_{0 \rightarrow \infty}$.

\section{Discussion}

The objective of this study was to characterize the in vitro dissolution as well as the absorption kinetics of ASA from a new orally disintegrating tablet formulation of lowdose ASA (ODA), Fasprin ${ }^{\circledR}$, with focus on the time of the earliest systemic exposure of ASA. Since the ODA product was designed to disintegrate rapidly in the mouth, it was not surprising that it demonstrated higher dissolution rate of ASA relative to the other leading ASAcontaining products tested in this study. With time, though, the extent of dissolution from enteric-coated aspirin started to catch up with that from Fasprin ${ }^{\circledR}$. While the differences in the dissolution rate data in this study might not bear clinical significance, it is reasonable to assume that Fasprin ${ }^{\circledR}$ can provide ASA levels at a faster rate compared to the other aspirin-containing products evaluated in this study, which could be valuable when a fast onset of ASA action is desirable.

The ODA product provided quantifiable concentrations of ASA to the systemic circulation in all subjects. While the time for the ODA formulation to disintegrate was variable, in this study, the dosage form completely disintegrated within four minutes, with seven of ten subjects reporting complete disintegration in less than two minutes. Although there was a lag-time prior to systemic exposure to ASA in all subjects, $50 \%$ percent of the subjects had quantifiable ASA plasma concentrations by 5 minutes and $100 \%$ of the subjects had ASA in the plasma by 15 minutes. This short time for the first quantifiable concentration of ASA can be attributed, at least in part, to the rapid disintegration and subsequent dissolution of the dosage form.

It is worth mentioning, though, that if the ODA product is to be administered chronically, for example, for its beneficial cardiovascular effects, rapid dissolution in the mouth might not be a clear advantage over other conventional ASA-containing products designed for oral administration for this purpose.

The plasma concentrations of ASA increased steadily in individual subjects after dosing until approximately 35 to 45 minutes when concentrations began to "level off" briefly prior to decreasing within the terminal elimination phase. A potential reason for this absorption pattern is that ASA from the ODA product started to get absorbed from the oral cavity soon after disintegration and then as the product, which is now in solution form or fine particles, started moving down the gastrointestinal tract, it continued to be absorbed from there as expected. The process of swallowing more and more of the product over time seems to be responsible for the observed slight "leveling off" of plasma levels of ASA, as well as the appearance of a blunt, instead of a sharp, $C_{\text {max }}$. Continued swallowing of portions of the product would be anticipated as natural swallowing occurs relatively frequently until the oral cavity is depleted from any ASA. One study noted spontaneous swallowing occurred at a rate of 1.32 swallows per minute [12].

The median $t_{\max }, 30$ minutes, was similar to values reported for other immediate-release solid dosage forms of aspirin [10, 14]. The median $t_{\max }$ for those subjects who fasted was 30 minutes and for those who did not fast, the value was 40 minutes. No significance can be applied to the difference as the small sample size precludes formal statistical analysis. The overall mean $\mathrm{C}_{\max }$ value was $0.61 \pm 0.34 \mu \mathrm{g} / \mathrm{mL}$, corresponding to a variability of $55.7 \%$ as represented by C.V.; the coefficient of variation. When looking at the subpopulations, the variability was 21.3 and $86.9 \%$ for fasting and non-fasting groups, respectively. While a large sample population is required to confirm this observation, there appears to be greater variability in $\mathrm{C}_{\max }$ in the non-fasting sub-population suggestive of food effect impacting the absorption of ASA from the DOA product.

Charman WN et al. [13] evaluated the absorption kinetics of another low-dose (75 mg) controlled-release formulation of ASA. While the two formulations differ in their design, the extent of ASA absorption from both dosage forms, represented by $\mathrm{AUC}_{0 \rightarrow \infty}$, was similar, $32.0 \pm 7.5$ and $37.9 \pm 10.1 \mu \mathrm{g} / \mathrm{mL} \times$ min for the controlled-release formulation and the ODA product, respectively, upon dose normalization. The $\mathrm{CL} / \mathrm{F}$ values in four subjects were similar to values reported earlier [10]. In the remaining five subjects, in whom pharmacokinetic parameters could be calculated, the $\mathrm{CL} / \mathrm{F}$ values were somewhat higher than reported earlier [10]. The terminal $t \frac{1}{2}$ of ASA averaged 28.3 minutes. This value is slightly longer than reported for most other immediate-release ASA dosage forms [10, 14]. Whether clinically significant or not, this prolonged $t \frac{1}{2}$ of 17.5 $34.3 \%$ may be a consequence of the dosage form design of the ODA product and/or repetitive swallowing of some of the disintegrated tablet particles over time, such that the input of the dose continued, even in slight proportions, for some time throughout the sampling period and possibly within the early portion of the elimination phase.

\section{Conclusion}

The orally disintegrating tablet formulation of low-dose aspirin (ODA) under investigation, known as Fasprin ${ }^{\circledR}$, provided systemic concentrations of ASA at a relatively early time. The fact that the ODA disintegrates rapidly in the oral cavity is significant. This is because the formed ASA-containing solution/suspension will start getting absorbed from the oral cavity first, resulting in quantifiable levels in plasma early on, and then continue to the major site of absorption in the gastrointestinal tract. The faster ASA goes into the solution/suspension state, as with an orally disintegrating formulation, the more likely absorption will occur sooner. Overall, the absorption-related pharmacokinetic parameters of the ODA product were generally comparable to those from 
other low-dose ASA-containing products. While the main objective of this study was to evaluate the in vitro dissolution characteristics and the absorption kinetics of ASA from the ODA product, a direct multi-dosage form, cross-over design study would be appropriate for comparative absorption characterization of ASA from this ODA product in relation to other ASA-containing oral dosage forms.

\section{Acknowledgement}

We would like to acknowledge the contributions of Matt Tupps, PharmD and Kate Turkaly, PharmD in the collection, analysis and reporting of data for the dissolution as well as the pharmacokinetic studies. Their assistance was valuable and highly appreciated.

\section{References}

[1] The Medical Research Council's General Practice Research Framework (1998) The Lancet, 351: 233-241.

[2] Ridker P.M., Cook N.R., Lee I.M., Gordon D., Gaziano J.M., Manson J.E., Hennekens C.H. and Buring J.E. (2005) The New England Journal of Medicine, 352 (13): 1293-1304.

[3] Hennekens C.H., Buring J.E., Sandercock P., Collins R., Peto R. (1989) Circulation, 80: 749756.

[4] Pedersen A.K. and FitzGerald G.A. (1984) The New England Journal of Medicine, 311 (19): 1206-1211.

[5] Harvey R., Champe P., Finkel R., Cubeddu L. and Clark M. (2009) Lippincott's Illustrated
Reviews: Pharmacology, $4^{\text {th }}$ Edition, Lippincott Williams \& Wilkins, p.233.

[6] FitzGerald G.A. and Shipp E. (1992) Annals of Epidemiology, 2:529-542.

[7] Flossmann E. and Rothwell P.M. (2007) The Lancet, 369: 1603-1613.

[8] Rothwell P.M., Wilson M., Elwin C.E., Norrving B., Algra A., Warlow C.P. and Meade T.W. (2010) The Lancet, 376: 1741-1750.

[9] Gjellan K., Magnusson A.B., Ahlgren R., Callmer K., Christensen D.F., Espmarker U., Jacobsen L., Jarring K., Lundin G., Nilsson G. and waltersson J.O. (1997) International Journal of Pharmaceutics, 151: 81-90.

[10] Benedek I.H., Joshi A.S., Pieniaszek H.J., King S.Y. P. and Kornhauser D. (1995) The Journal of Clinical Pharmacology, 35:1181-1186.

[11] Bolton S. (1997) Pharmaceutical Statistics, Practical and Clinical Applications, $3^{\text {rd }}$ Edition, New York: Marcel Dekker.

[12] Afkari S. (2007) Australasian Physical and Engineering Sciences in Medicine, 30(4): 313317.

[13] Charman W.N., Charman S.A., Monkhouse D.C., Frisbee S.E., Lockhart E.A., Weisman S. and Fitzgerald G.A. (1993) British Journal of Clinical Pharmacology, 36(5): 470-473.

[14] Bochner F., Somogyi A.A. and Wilson K.M. (1991) Clinical Pharmacokinetics, 21(5): 394399.

Table 1 - Subject demographics

\begin{tabular}{llll}
\hline $\begin{array}{l}\text { Subjects } \\
(3 \mathrm{M} / 7 \mathrm{~F})^{\mathrm{a}}\end{array}$ & $\begin{array}{l}\text { Age } \\
\text { (years) }\end{array}$ & $\begin{array}{l}\text { Height } \\
\text { (inches) }\end{array}$ & Weight (kilograms) \\
\hline Mean & 28.2 & 66.5 & 70.1 \\
S.D. & 11.9 & 3.8 & 16.2 \\
Minimum & 21 & 61 & 52.3 \\
Maximum & 54 & 73 & 100
\end{tabular}

${ }^{*}$ Five subjects fasted at least eight hours prior to dosing. ${ }^{a}$ M: Male; F: Female $\quad$ b S.D.: Standard deviation

Table 2 - In vitro dissolution parameters of ASA from the different ASA-containing products

\begin{tabular}{lcc}
\hline Dosage Form & Dissolution Rate (\%/min) & Extent of Dissolution (\%) \\
\hline Fasprin® $81 \mathrm{mg}$ & ${ }^{*} 3.53 \pm 0.29 \mathrm{a}$ & ${ }^{*} 92.03 \pm 6.05^{\mathrm{a}}$ \\
Bayer® $81 \mathrm{mg}$ Chewable & ${ }^{*} 2.71 \pm 0.42$ & $76.08 \pm 10.19$ \\
Bayer® $81 \mathrm{mg}$ Enteric-Coated & $2.49 \pm 0.46$ & ${ }^{*} 88.05 \pm 5.68$ \\
Bayer® $325 \mathrm{mg}$ & $2.07 \pm 0.25$ & $82.24 \pm 3.57$ \\
\hline
\end{tabular}

$\left(^{*}\right)$ Significantly higher than unmarked values, $\left(^{* *}\right)$ significantly higher than values marked with $\left(^{*}\right)$ : One-way ANOVA followed by Tukey's post-hoc analysis, $P<0.05$ a Values represent mean \pm S.D. $(n=5-7)$.

Table 3 - Disintegration time of the ODA product (Fasprin $®)$ on the tongue

\begin{aligned} \hline Subjects $^{*} \mathrm{n}=10 &$ Disintegration Time (seconds) \\ \hline Mean & 111.2 \\ S.D. & 65.2 \\ Minimum & 45 \\ Maximum & 239\end{aligned}

${ }^{*}$ Five subjects fasted at least eight hours prior to dosing. 
Table 4 - Pharmacokinetic parameter estimates for ASA upon single oral dose of the ODA product (Fasprin®)

\begin{tabular}{|c|c|c|c|c|c|c|}
\hline $\begin{array}{l}\text { Subjects* } \\
n=9\end{array}$ & $\begin{array}{l}\text { Tmax } \\
\text { (minutes) }\end{array}$ & $\begin{array}{l}\text { Cmax } \\
(\mu \mathrm{g} / \mathrm{mL})\end{array}$ & $\begin{array}{l}\lambda z \\
\left(\text { minutes }^{-1}\right)\end{array}$ & $\begin{array}{l}t^{1} 1 / 2 \\
\text { (minutes) }\end{array}$ & $\begin{array}{l}\mathrm{AUC}_{0 \rightarrow \infty} \\
(\mu \mathrm{g} / \mathrm{mL} \times \mathrm{min})\end{array}$ & $\begin{array}{l}\mathrm{CL} / \mathrm{F} \\
\text { (mL/minute) }\end{array}$ \\
\hline $\begin{array}{l}\text { Mean } \\
\text { S.D. } \\
\text { C.V. }(\%)^{d}\end{array}$ & $\begin{array}{l}30^{\mathrm{a}} \\
(25,75)^{\mathrm{b}} \mp\end{array}$ & $\begin{array}{l}0.61 \\
0.34 \\
55.7\end{array}$ & $\begin{array}{l}0.0245 \\
0.0078 \\
31.8\end{array}$ & $28.3^{c}$ & $\begin{array}{l}37.9 \\
10.1 \\
26.6\end{array}$ & $\begin{array}{l}2282 \\
636 \\
27.9\end{array}$ \\
\hline
\end{tabular}

${ }^{*}$ Five subjects fasted at least eight hours prior to dosing.

a Median; $\mathrm{b}$ Range; $\mathrm{c}$ Harmonic mean

${ }^{d}$ C.V. (\%): Coefficient of variation $\%=($ mean / S.D. $) \times 100 \%$

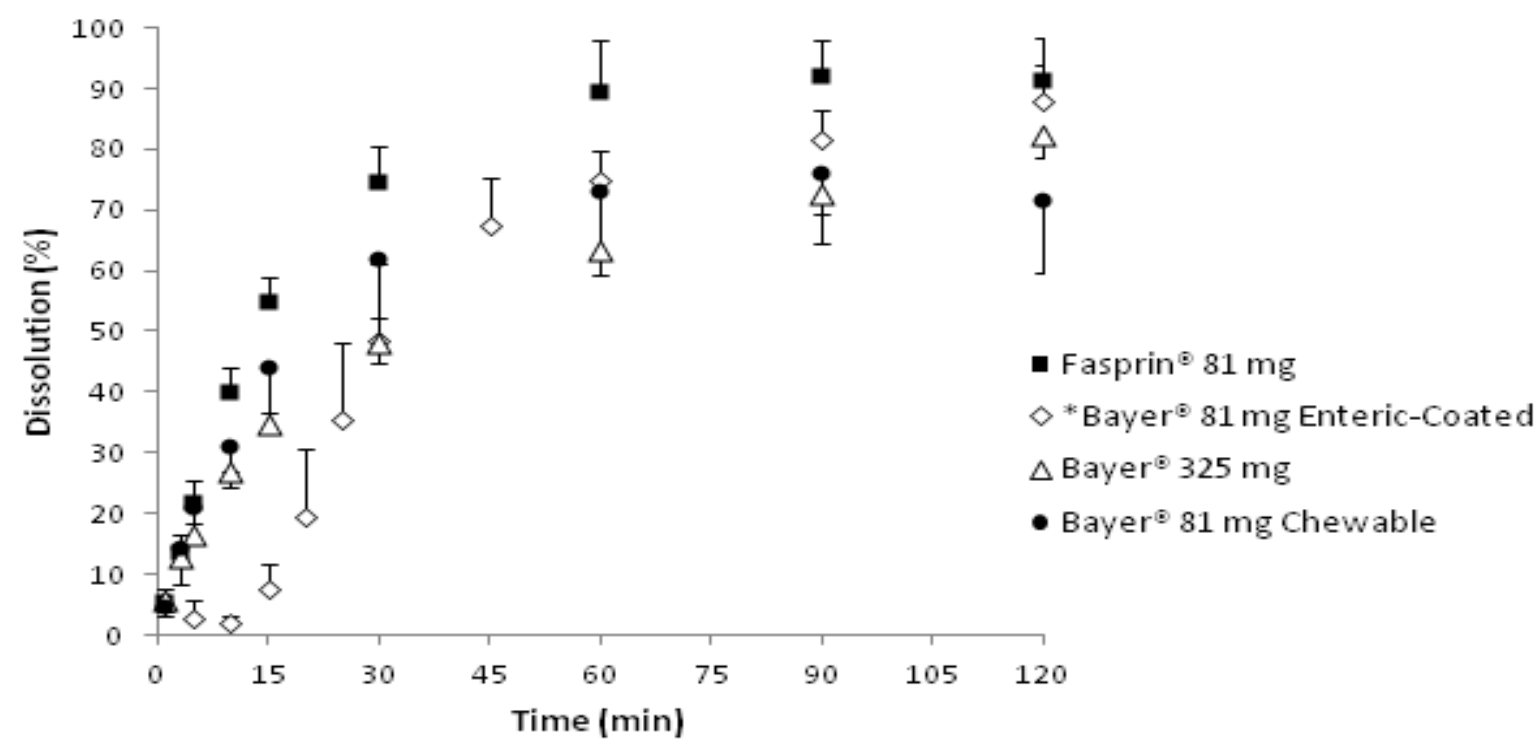

Fig. 1-In vitro dissolution profiles of ASA from the different ASA-containing products

*Data for Bayerß $81 \mathrm{mg}$ enteric-coated tablets represent those collected after the switch in the dissolution medium as per the methods section.

Bars denote S.D.

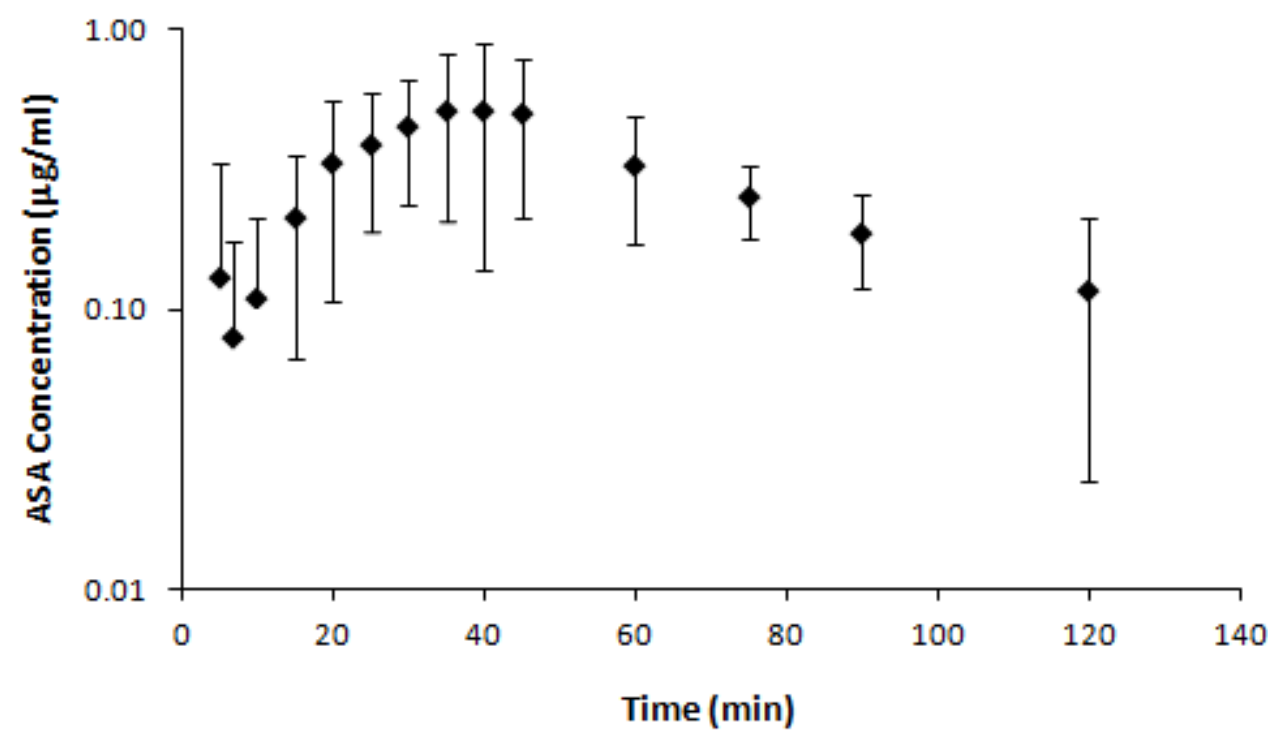

Fig. 2-Plasma concentration vs. time profile of ASA upon single oral dose of the ODA product (Fasprin $®),(n=9)$ 